\title{
Compendium of Innovative Practice: Learning Development in a Time of Disruption
}

\section{Editorial}

\author{
Alicja Syska \\ University of Plymouth
}

When Covid-19 first eclipsed our collective consciousness in early 2020, few people could predict how long it would last and what toll it would take on the HE sector across the globe. Initially, we sought deliverance in technology, revelled in online quizzes, fumbled with our video cameras and desperately tried to remember to unmute ourselves. High on adrenaline and in true entrepreneurial spirit, we created countless digital resources, explored new teaching approaches, and stretched our creativity in order to adapt to this crisis mode. It took a while before we realised that what seemed like a temporary disruption would in fact force us to rethink the way we work, teach, learn, socialise, and relate to each other.

The aim of this Compendium was to capture that moment of disruption. As the 'pandemic fatigue' (Haktanir at al., 2021) began to slow us down and the world started racing to return to some kind of 'normal', we in the JLDHE were racing to gather the immediate and unmediated stories that would reflect on this unique moment, still almost 'in action' rather than 'on action' (Schön, 1991). We issued a call for submissions in April 2021 and by the June deadline had responses from over a hundred authors. We enlisted 114 reviewers, most of whom commented on multiple submissions, who helped us select and guide the final 102 articles to publication. The brief for the authors was simple: (1) present the challenge you faced, cared about, and decided to address; (2) explain how you responded to it; (3) make recommendations based on the lessons learnt from the experience. All submissions had to follow this 3-part structure and conform to the unforgiving 1,000 word limit. We must say that colleagues' response to this call surpassed all our expectations.

When we looked at all the submissions, clear themes emerged. Some authors report on their battles to adapt their learning development practices while others tell stories of 
challenges encountered in teaching within specific disciplines. A good number of reflections focus on student engagement and student and staff wellbeing, while others are interested in assessment and feedback, students as partners, and the experience of doctoral researchers. We have authors who tell their tales of discovering and grappling with new technologies and those who bring our attention back to the body. Finally, there is substantial preoccupation with staff support and institutional change. The emerging themes naturally lent themselves to distinct sections of this Compendium, each prefaced by an editorial that introduces its topical essence and reflects on the authors' approaches.

What emerges from all these Compendium articles is an absolutely astounding range of individual and institutional responses, reflections and recommendations for future educational practice. They show what was important to us and what we struggled with; how much faith we put in tools and technology and how we established connections through kindness and compromise; what flaws we discovered in the system and what radical solutions we were prepared to risk to humanise ours and our students' experience. They are also written in different styles and from different perspectives. As a result, the collection is very eclectic and at times perhaps even disorderly. It was challenging to organise and we heatedly debated what theme each article belonged to while agonising over the need to avoid specious designations where multiple possibilities emerged. The eleven categories we created at times are obvious and at times might seem forced. The readers must forgive us as this mammoth task was never going to produce consistent, predictable and ordered results. Instead, we shamelessly (for this is the essence of learning development work after all!) welcome you into this playful, messy and creative world of educators who generously and enthusiastically share their resourcefulness, ingenuity, and love for working with students in HE.

Crucially, many of the contributions in this volume do not simply report on their responses to the online pivot but raise profound questions about what it means to teach and learn in emergency conditions, what impact such crises can have on our physical and mental health, and how we might use this disruption to shift our pedagogic assumptions about what 'works best' and how to turn vulnerability into strength. What all of them reveal is that even when violently thrown off course, confined to our rooms and screens, and seemingly challenged beyond our imagination, we can still see in this collective catastrophe a silver lining and turn apparent limitations into opportunity. What seems like a disconcerting state of personal and institutional disintegration can in fact be understood as an element of 
personal and institutional development. As the Polish psychiatrist Kazimierz Dąbrowski (1964) demonstrated in his theory of 'positive disintegration', states of crisis and disequilibrium should be seen as positive signs because they accelerate our growth; if 'successfully navigated', they become an opportunity for positive change and a catalyst that allows us to become 'the best version of ourselves' (Schläppy, 2019). The role of this upheaval thus should be to help us restructure the existing and often unhelpful patterns of working, teaching, and learning in order to lift us higher on the level of professional and personal development. This Compendium is a clarion call to adopt this productive approach to the impact of the pandemic.

As always with an undertaking of this size and scope, there are scores of people who not only support the effort but actually roll up their sleeves and make it happen. My first thanks go to the three exceptional co-editors - Gita Sedghi, Cathy Malone, and Nicola Grayson who believed in my mission for the Compendium from the start and who worked tirelessly to coordinate multiple submissions, often stepping in to review, mentor, and perform never-ending little tasks in a complex editorial flow. It is you who made this Compendium happen. Our copyeditors - Harriet Newnes, Sarah Taylor, Laura Barclay, and Ricky Lowes - were as indefatigable in their positive responses to our incessant requests for copyediting; we are so grateful for your professionalism, attentiveness, and collegiality. Our technical editor Andy Hagyard helped us avert various crises and shape the volume ensuring consistency and quality. Finally, our deepest gratitude goes to all the reviewers who offered their comments, suggestions, and support to our authors. Without your enthusiasm and willingness to review sometimes multiple papers and to generously give your time and share your expertise, this Compendium would not have been what it is. A silent but heartfelt round of applause thus goes to the following reviewers:

Aileen Breed Hanrahan

Alan Hayes

Alex Liepins

Alexandra Pitt

Alicja Syska

Alison Gilmour

Alistair Irons

Ameera Ali

Amy West
Anne Elizabeth Davey

Annie Bryan

Arina Cirstea

Beth Moran

Bridget Goodman

Camila Devis-Rozental

Carina Buckley

Carlene Barton

Caroline Havery
Cathy Malone

Celeste McLaughlin

Christie Pritchard

Claire McAvinia

Claire Pike

Craig Morley

David Heading

Deborah Breen

Deryn Verity 


\begin{tabular}{|c|c|c|}
\hline Eleanor Loughlin & Kevin Merry & Rosemarie Mcllwhan \\
\hline Emily Forster & Kim M. Mitchell & Sabina Cerimagic \\
\hline Erika Corradini & Kimberly Hoffman & Samantha Aston \\
\hline Eva Shackel & Laurie Walden & Samantha Jane Ahern \\
\hline Faith Dillon-Lee & Lee Fallin & Samantha Thomas \\
\hline Fiona Elsted & Letizia Gramaglia & Sara Bird \\
\hline Gemma Stansfield & Linda Weinberg & Sarah Honeychurch \\
\hline Geoffrey Hughes & Liz Wilding & Sarah Wolfenden \\
\hline Gita Sedghi & Lucinda Becker & Scott Farrow \\
\hline Hazel Messenger & Lucy Gill-Simmen & Sharon Perera \\
\hline Ian Paul Johnson & Luis Pereira & Silvina Bishopp-Martin \\
\hline Isabel Lucas & Lynn Gribble & Simon A Williams \\
\hline Jacqui Bartram & Małgorzata Drewniok & Simon Strange \\
\hline Jamie Rundle & Margaret Rachael Scott & Siobhan Hawke \\
\hline Jane Nodder & Maria Kukhareva & Sophie Leslie \\
\hline Jane Turner & Mary Jacob & Stacey Mottershaw \\
\hline Jiani Liu & Matt Hardy & Steph Doehler \\
\hline John Parkin & Neil Ford & Stephen Mark Rutherford \\
\hline John Smith & Neil Kramm & Steve Peters \\
\hline Josta Heyligers & Nicky Turnbull & Stevie Prickett \\
\hline Joy Igiebor & Nicola Clarke & Susan Halfpenny \\
\hline Julia Bohlmann & Nicola Meryl Pallitt & Tamsin Kilner \\
\hline Karen Angus-Cole & Nkaepe Olaniyi & Teeroumanee Nadan \\
\hline Karen Clark & Peggy Murphy & Vicky Collins \\
\hline Karen Kenny & Peter Hartley & Victoria Elizabeth Mann \\
\hline Kate Coulson & Qian Zhang & Victoria Rafferty \\
\hline Katerina Loukopoulou & Ralitsa B. Kantcheva & Virna Rossi \\
\hline Katharine Stapleford & Rebecca Cohen & Weijia Li \\
\hline Katy Jones & Robert Ping-Nan Chang & Zoe Enstone \\
\hline
\end{tabular}

We are very proud of what this Compendium says about our community and hope that our readers will find in it a source of inspiration, information and encouragement.

On behalf of the Editorial Board, Alicja Syska 


\section{References:}

Dąbrowski K. (1964) Positive Disintegration. Boston, MA: Little Brown.

Haktanir, A., Can, N., Seki, T., Kurnaz, M. F. and Dilmaç, B. (2021) 'Do we experience pandemic fatigue? Current state, predictors, and prevention', Current Psychology, 112. https://doi.org/10.1007/s12144-021-02397-w.

Schläppy, M. L. (2019) 'Understanding mental health through the theory of positive disintegration: A visual aid', Frontiers in psychology, 10:1291. https://doi.org/10.3389/fpsyg.2019.01291.

Schön, D. A. (1991). The reflective practitioner: How professionals think in action. Aldershot: Ashgate Publishing Ltd. 